\title{
The intensity of physical activity influences bone mineral density in healthy young males
}

\author{
M. S. Barnes ${ }^{1}$, G. Horigan ${ }^{1}$, K. L. Rennie ${ }^{2}$, M. P. Bonham ${ }^{1}$, E. M. Duffy ${ }^{1}$, J. J. Strain ${ }^{1}$ \\ and J. M. W. Wallace ${ }^{1}$ \\ ${ }^{1}$ Northern Ireland Centre for Food \& Health (NICHE), University of Ulster, Coleraine BT52 1SA, UK and \\ ${ }^{2}$ Unilever Corporate Research, Colworth House, Sharnbrook, Bedfordshire MK44 1LQ, UK
}

Osteoporosis is a major cause of morbidity and mortality through its association with fracture risk ${ }^{(1)}$. Attainment of maximum peak bone mass and retarding natural bone loss with age are critical in reducing the frequency and severity of osteoporosis. An active lifestyle is a key factor in both the development and maintenance of bone mineral density (BMD), with the effect of physical activity (PA) on BMD apparently dependent on duration and intensity ${ }^{(2,3)}$. The influence of PA intensity on bone health in early adulthood has not been widely studied; therefore, the aim of the present study was to assess the associations between PA intensity and BMD in young adults.

Apparently-healthy 20-40-year-old males and females ( $n$ 105; forty-eight males and, fifty-seven females) completed a PA questionnaire $^{(4)}$. Metabolic equivalent hours (MET) were calculated for each recreational activity and were classified in terms of intensity as low (LOW; MET <3), moderate (MOD; MET $\geq 3>6$ ) or vigorous (VIG; MET $\geq 6$ ) PA and summed as total h/week. BMD was measured at the lumbar spine, total femur and total body by dual-energy X-ray absorptiometry using a Lunar Prodigy scanner (GE Lunar, Madison, WI USA; software version 11). Males had a significantly higher BMD of the total femur $(P<0.0001)$ and total body $(P<0.0001)$ than females and spent significantly more time (median; h/wk) in all activities (9.68 males $v .4 .50$ females; $P<0.0001)$, MOD PA (4.96 v. 3.40 ; $P=0.013)$ and VIG PA $(2.96 v .0 .24 ; P<0.0001)$ than females. Gender-specific multiple regression analysis was conducted to assess the associations between PA intensity (time spent in PA; h/week) and BMD controlling for age, height and weight (Table).

\begin{tabular}{|c|c|c|c|c|c|c|c|c|c|c|c|c|}
\hline \multirow[t]{3}{*}{ BMD....... } & \multicolumn{4}{|c|}{ Lumbar spine } & \multicolumn{4}{|c|}{ Total femur } & \multicolumn{4}{|c|}{ Total body } \\
\hline & \multicolumn{2}{|c|}{ Males $(n 48)$} & \multicolumn{2}{|c|}{ Females ( $n$ 57) } & \multicolumn{2}{|c|}{ Males $(n$ 48) } & \multicolumn{2}{|c|}{ Females $(n$ 56) } & \multicolumn{2}{|c|}{ Males $(n$ 48) } & \multicolumn{2}{|c|}{ Females ( $n$ 57) } \\
\hline & $\beta$ & $P$ & $\beta$ & $P$ & $\beta$ & $P$ & $\beta$ & $P$ & $\beta$ & $P$ & $\beta$ & $P$ \\
\hline Total PA & 0.552 & 0.0001 & -0.070 & 0.604 & 0.476 & 0.0001 & 0.067 & 0.577 & 0.638 & 0.0001 & -0.051 & 0.677 \\
\hline LOW PA & -0.129 & 0.507 & -0.285 & 0.103 & -0.086 & 0.601 & -0.160 & 0.335 & -0.261 & 0.109 & -0.290 & 0.078 \\
\hline MOD PA & 0.360 & 0.027 & -0.125 & 0.349 & 0.218 & 0.060 & 0.047 & 0.691 & 0.402 & 0.006 & -0.050 & 0.672 \\
\hline VIG PA & 0.577 & 0.0001 & 0.016 & 0.921 & 0.410 & 0.006 & -0.117 & 0.409 & 0.525 & 0.0001 & -0.152 & 0.294 \\
\hline
\end{tabular}

Total time (h/week) in all PA and in MOD and VIG PA were positively associated with BMD of the lumbar spine, total femur and total body in males. PA was not associated with BMD at any site in females. In conclusion, MOD and VIG PA positively influences BMD in young healthy males but not in females. It is speculated that there might be a threshold of time spent in PA of sufficient intensity that is required to promote bone health, which perhaps the young women in the current study did not achieve. Whilst current public health messages focus on increasing overall PA levels, the present research suggests that time spent in PA should be at least MOD to have beneficial effects on bone.

We would like to acknowledge the Food Standards Agency for their support.

1. Dontas IA \& Yiannakopoulos CK (2007) J Musculoskelet Neuronal Interact 7, 268-272.

2. Kerr D, Morton A, Dick I \& Prince R (1996) J Bone Miner Res 11, 218-225.

3. Mazess RB \& Barden HS (1991) Am J Clin Nutr 53, 132-142.

4. Ginty F, Rennie KL, Mills L, Stear S, Jones S \& Prentice A (2005) Bone 36, 101-110. 